\title{
Treating depression with exercise: The inflammasome inhibition perspective
}

\author{
Roberta de Paula Martins ${ }^{1,2}$, Chai K Lim ${ }^{2}$, Karina Ghisoni ${ }^{1}$, Ananda Staats ${ }^{1}$, Karine Dallagnol ${ }^{1}$, Alexandre Solano ${ }^{1}$, Gilles J. Guillemin ${ }^{2}$, \\ Aderbal Silva Aguiar Jr ${ }^{1}$ and Alexandra Latini ${ }^{*}$ \\ ${ }^{1}$ Laboratory of Bioenergetics and Oxidative Stress - LABOX, Department of Biochemistry, Federal University of Santa Catarina, Campus Universitário, Córrego \\ Grande, Florianópolis, SC, Brazil \\ ${ }^{2}$ Faculty Medicine and Health Sciences, Macquarie University, North Ryde, New South Wales, Australia
}

\begin{abstract}
Patients with chronic inflammation present increased blood levels of circulating cytokines and often are associated with symptoms of depression. The activation of the immune cells microglia in the brain of depressed patients has been associated with a greater prevalence of suicide, indicating a crucial role of neuroinflammation in the neuropathology of depression. In the modern lifestyle, decreased physical activity and increased sedentarism have emerged as risk factors for mental disorders, including depression. The literature is very consistent that exercise is an antidepressant; however, the molecular mechanisms responsible for these beneficial effects are far from being completely defined. We present evidence on the role of exercise in reducing neuroinflammation and inhibiting the assembly of the inflammasome in the context of depression, focusing on the potential immunomodulatory role of the biomarker neopterin.
\end{abstract}

\section{Introduction}

\section{Depression and inflammasome activation}

Depression affects up to $20 \%$ of the population worldwide, leading to a substantial social impact [1]. Major depressive disorder (MDD) is a common neurological disorder mainly characterized by depressed mood, low self-esteem and anhedonia. It is often accompanied by disrupted sleeping, eating, and impaired cognition, fatigue, aches, pain, digestive problems, reduced energy, among others [2,3]. Thus, it is considered a widespread, devastating and chronic illness, which causes profound socioeconomic burden and negative impact on the functioning and the quality of life of patients $[2,4]$. The physiopathology of depression is influenced by environmental and genetic factors, including social relationships and specific alterations in genes' coding, i.e., neurotrophic factors, like brain-derived neurotropic factor (BDNF) or brain signaling molecules such as 5-hydroxytryptamine (5-HT), whose deficiency compromises many neuronal functions. In addition, the physiopathology of depression has been associated with increased oxidative stress status [5], mitochondrial dysfunction [6], reduced neurogenesis [7] and chronic inflammation [8].

Inflammation is a protective and coordinated response to cellular stress that results from the elegant communication among different types of immune cells. Acute inflammation is an early and almost immediate tissue response, i.e., to injury. It is non-specific, of short duration, and occurs before the immune response is established. At this stage, the main objective of the immune response is to remove the cellular stress: injury, injurious agents, foreign bodies or aka hypersensitivity reactions. On the other hand, chronic inflammation is not a part of the natural healing process, and eventually chronic inflammation will cause organ damage, including mental illness, since the body is not prepared to cope with persistent unfocused immune activity.
The inflammatory response is coordinated by cytokines, immunomodulatory molecules typically produced by immune cells [9]. The immune response can be either toxic or protective, depending on the signals the immune cells receive. The functions of the different cytokines are very complex and will also depend on the context and the concentration in relation to one another. Cytokines such as interleukin-6 (IL-6), tumor necrosis factor- $\alpha$ (TNF- $\alpha$ ), interferon- $\gamma$ (IFN- $\gamma$ ), and interleukin-1 $\beta$ (IL-1 $\beta$ ) are considered to have profound pro-inflammatory functions. On the contrary, cytokines such as interleukin-4 (IL-4) and interleukin-10 (IL-10) are considered to have anti-inflammatory properties [9].

Pro-inflammatory cytokines are mainly produced by immune cells, such as macrophages, neutrophils, natural killer cells, microglia and astrocytes. These cells are activated by the recognition of noxious stimuli originated from pathogens or the host it, which is mediated by molecular sensors, collectively called pattern recognition receptors. Their activation leads to signaling pathways that can culminate in the induction of transcription factors, as the kappa B nuclear factor (NF$\mathrm{kB}$ ), a master pro-inflammatory transcription factor which induces the synthesis of most pro-inflammatory cytokines (e.g., TNF- $\alpha$, IL-1, IL-6, IL-8, and IL-12).

Most cytokines due to the presence of signal peptides in its structure

Correspondence to: Alexandra Latini, Laboratory of Bioenergetics and Oxidative Stress, LABOX. Department of Biochemistry, Center of Biological Sciences, Federal University of Santa Catarina - UFSC, Florianópolis - SC, 88040-900, Brazil, Tel: +55 48 37214743; Fax: +55 48 37219672; E-mail: a.latini@ufsc.br

Key words: Physical exercise, depression, Inflammasome, neopterin, neuroprotection

Received: November 21, 2016; Accepted: December 13, 2016; Published: December 17, 2016 
are released through classical secretory pathways after being packaged in the Golgi and secreted by receptor-mediated release [10-12], or by constitutive exocytosis upon their synthesis through the recycling of endosomes and small secretory vesicles $[13,14]$. Cytokines lacking the signal peptide required for endoplasmic reticulum entry are released from the cells by non-classical pathways [15]. A well-known example is the pro-inflammatory cytokine IL- $1 \beta$, which is first generated as the biologically inactive pro-IL- $1 \beta$, and needs to be processed in its mature form to be released and then exert its functions [16]. This processing is usually mediated by caspase-1 [17]; however, some studies have identified that pro-IL- $1 \beta$ processing can also be mediated by neutrophil- and macrophage-derived serine proteases such as proteinase-3, elastase, and cathepsin-G $[18,19]$. Thus, this caspase1 -independent activation of pro-IL- $1 \beta$ is likely to occur in situations when neutrophils are the major cell population in the inflammatory infiltrate.

Caspase- 1 is a protease synthesized as an inactive zymogen of 45 $\mathrm{kDa}$ consisting of a CARD and two subunits, p20 $(20 \mathrm{kDa})$ and p10 $(10 \mathrm{kDa})$, which together form the protease pro-domain. Pro-caspase-1 activation is mediated by the inflammasome, a cytosolic protein complex, that functions as a platform for the assembly of two or more pro-caspases, allowing its proteolytic self-cleavage and the formation of an enzymatically active heterodimer composed of the subunits p20 and $\mathrm{p} 10[20,21]$.

The inflammasome is composed of i) a sensor/receptor protein located in the cytosol that serves as a platform for the formation of the complex, ii) an adapter protein, ASC [apoptosis-associated speck-like protein containing a CARD (caspase recruitment domain)], and iii) an effector protein, caspase-1 [20]. The inflammasome formation facilitates self-cleavage and the activation of caspase-1, which proteolytically will cleave and allow the activation of two other pro-inflammatory cytokines, IL-1 $\beta$ and IL-18 [17]. Pro-IL-1 $\beta$ and pro-IL-18 cytokines in their mature forms will favor, therefore, pro-inflammatory and antimicrobial responses [22,23].

There are four conventional or canonical inflammasomes which process pro-IL-1 $\beta$ and pro-IL-18 via caspase-1: the NLRP1 (NLR family protein, containing pyrin domain 1), NLRP3, IPAF (IL-1converting enzyme protease-activation factor) and AIM2 (absent in melanoma 2). These inflammasomes differ primarily in structure, requirement of the accessory protein ASC and potential activators. The NLRP3 inflammasome is the most studied and best characterized inflammasome due to its ability to detect both pathogen- and damageassociated molecular patterns. In addition, emerging data have demonstrated its activation in brain regions from different species, for example, in the cerebral cortex [24] and hippocampus [25] of mice; in the cerebral cortex [26,27], hippocampus [25], and striatum [28] of rats, and in the frontal cortex [29] and hippocampus [30] of humans.

Although the inflammasome assembly is essential for host defense, recent studies have shown that the persistent activation of this complex is involved in the pathogenesis of various inflammatory chronic diseases, including peripheral chronic conditions such as type 2 diabetes and central nervous system (CNS) disorders, including Parkinson's and Alzheimer's diseases and depression [31-33]. In this scenario, data from clinical studies have shown that MDD-affected patients present increased expression of NLRP3 and caspase- 1 in blood cells and increased IL-1 $\beta$ and IL-18 levels in the serum, which were reduced after an amitriptyline treatment [34]. Additionally, experimental studies have shown that mice submitted to chronic unpredictable mild stress presented increased content of IL-1 $\beta$, caspase-1 and NLRP3 in the hippocampus and/or cortex [35,36]. Furthermore, the genetic deficiency of caspase-1 decreased depressiveand anxiety-like behaviors, increased locomotor activity, and prevented the exacerbation of depressive-like behaviors following chronic stress in these animals [37]. Finally, the administration of the inflammasome inhibitor VX-765 (a selective caspase-1 inhibitor) ameliorated depression- and anxiety-like behaviors and reversed the increased levels of IL-1 $\beta$ and IL-18 in the hippocampus of mice subjected to ovariectomy [38]. Therefore, the inhibition of inflammasome assembly seems to be a promising therapeutic target for depression.

\section{Treating depression with exercise}

Sedentarism and physical inactivity have emerged as additional risk factors for mental disorders, in the last 50 years [39]. Like depression, a sedentary lifestyle is becoming a prominent risk factor for a variety of non-communicable diseases: diabetes mellitus, cancer (colon and breast), obesity, and hypertension [40-46]. Conversely, sedentarism and physical inactivity are both modifiable risk factors $[40,41,47]$. Regular exercise brings a number of mental and physical health benefits, including improved cognitive and memory functions, bone and muscle density, enhanced immune response and reduced risk of developing diseases and syndromes characterized by chronic inflammation, including diabetes mellitus, obesity, heart disease, metabolic syndromes and cancer $[40,42-46,48,49]$.

Clinically, exercise has been a readily available therapeutic option, effective as a first-line treatment in mild to moderate depression [50,51]. Randomized and crossover clinical trials demonstrate the efficacy of aerobic or resistance training exercise as a treatment for depression in adults. The English Longitudinal Study of Ageing showed that depressive symptoms and low-grade inflammation were attenuated by physical activity intervention in 3,609 older adults. The exercise-induced benefits were evidenced even without any other intervention, by lower depressive scores when applying the Center for Epidemiological Scale - Depression (CES-D), and by reduced serum reactive protein $C$ levels, respectively [48]. When supervised aerobic physical exercise (45-50 min/week three times a week for four months) was combined with pharmacotherapy the scores for depression were also lower when applying the Beck Depression Inventory (BDI) and Depression, and the Anxiety and Stress Scales (DASS)-21 [52].

Not only long exercise programs have been shown to have antidepressant properties. Shorter protocols, including for example, two weeks of physical exercise (3 sessions/week) improved depressive symptoms and the physical and psychological domains of Quality of Life in hospitalized patients [53]. Furthermore, ten days of aerobic exercise (30 minutes walking on a treadmill/day) reduced the depression scores measured by the Hamilton Rating Scale for Depression (HAM-D) [54].

Exercise programs are effective in attenuating depressive symptoms in both young and older depressive patients. Regular physical exercise (50 min jogging sessions; 5 sessions/week, during 8 weeks) reduced HPA disruption by decreasing cortisol urinary levels in adolescent females with depressive symptoms assessed with the CES-D [55]. In another cohort, a combined program employing cognitive behavioral therapy associated with aerobic exercise (12 weeks) and nutritional orientation reduced body weight and attenuated depressive symptoms in obese depressive teenagers [56].

On the other side, adult MDD patients (around 50 years old) submitted to controlled aerobic exercise (3 times/week during 16 
weeks) showed better performances at the HAM-D and the BDI, comparable to the effects of the treatment with the anti-depressant sertraline hydrochloride [57]. Also, depressive symptoms and memory performance, evaluated by the Geriatric Depression Scale-15, and the Logical Memory subtests of the Wechsler Memory Scale-Revised, were also improved in 65 years old MDD patients submitted to aerobic exercise training (muscle strength training, postural balance retraining, and dual-task training activities during 20 weeks) [58]. These cognitive improvements in depressive patients could be linked to the physical exercise-induced BDNF production. In this context, it has been demonstrated that aerobic exercise increases serum BDNF levels and improves the Profile of Mood States in women diagnosed with MDD [59].

The success of exercise against depression is attributed to the improvement of various mechanisms including the enhancement of monoamine metabolism [60-62], neurotrophic factors formation and blood vessel density and neurogenesis [63-66], antioxidant status, mitochondrial activity, amid others [61]. Increased hippocampal monoamine content and enhanced monoamines signaling with reduced depressive-like behavior have been observed in mice submitted to voluntary exercise during three to six weeks in the running wheel (RW) $[60,61]$. Indeed, RW protocols have been extensively employed to unravel some of the molecular mechanisms involved in its inducedantidepressant-like effects in rodents. Examples are the enhanced mitochondrial gene expression and activity [61], the reduced endothelial mitochondrial superoxide production in aged mice [67] or the increased hippocampal neurotrophic factor expression, such as GDNF and BDNF [61]. Augmented expression of BDNF has also been demonstrated in other exercise protocols, including the downhill training [63] or the swimming training [64,68]. Also, increased expression of $c$-Fos, a biomarker of neuronal activity [69], has been shown to be upregulated in serotonergic neurons of the dorsal Rafe nuclei, resulting in attenuation of anxious and depressive-like behavior in rats submitted to low intensity aerobic exercise [70]; therefore, acknowledging the involvement of exercise in enhancing hippocampal neurogenesis, and dendritic plasticity [71]. Adiponectin, a hormone secreted predominantly from adipocytes with insulin-sensitizing, antidiabetic, anti-inflammatory, and antiatherogenic properties, that alone can mimic many of the metabolic effects of physical exercise, has also been linked to this effect. The hormone crosses the blood-brain barrier and acts on receptors located preferentially in the hippocampus [72], promoting neuronal differentiation. Yau and coworkers (2014) demonstrated that adiponectin deficiency does not compromise hippocampal neurogenesis, but diminished the effectiveness of exercise in increasing the process. In agreement, clinical studies have reported lower levels of plasma adiponectin in patients affected by depression [73], which could be increased after antidepressant treatments [74]. However, the mechanisms underlying the adiponectin antidepressive effects have not been defined yet.

Exercise also exerts overt anti-inflammatory effects, in part by promoting appropriate hypothalamic-pituitary-adrenal (HPA) axis function [64], by decreasing peripheral and/or hippocampal expression of immune-related genes $[66,75,76]$. For instance, chronic exposure to high levels of dexamethasone provoked, as expected, HPA disruption characterized by reduced blood corticosterone levels and adrenal cholesterol synthesis, and adrenal weight, which were prevented by a four week-swimming training protocol [64]. In agreement, voluntary exercise shorter the time to peak corticosterone and increased its decay speed following restraint stress, indicating that exercise induces a more efficient - rapid and shortened - HPA response [77].

The hippocampal or pre-frontal cortex pro-inflammatory profile, characterized by increased levels of IL- $1 \beta$, IL- 6, TNF- $\alpha$, IFN- $\gamma$ or indoleamine-pyrrole 2,3-dioxygenase have also been shown to be ameliorated after voluntary activity, and many other exercise protocols, including endurance training, running in a treadmill, swimming among others $[26,64,78,80,81]$.

\section{Focusing on the inhibition of inflammasome assembly to treat depression with exercise}

Recently, the anti-inflammatory effects of physical exercise were also demonstrated to be mediated by regulating the activation of the inflammasome. Mardare and colleagues (2016) showed that two endurance training protocols improved glucose tolerance and reduced biomarkers of inflammation and body weight in rodents treated chronically with a high fat diet (HFD) by reducing the increase of NLRP3 and IL-18 expression in adipose tissue [82]. Another recent work demonstrated that a physical exercise protocol of moderate intensity reduced the activation of NLRP3 inflammasome and the levels of IL-1 $\beta$ and IL-18 in the mouse hippocampus, and it also ameliorated the depression-like behavior induced by ovariectomy [83]. Cai and colleagues (2016) also reported that endurance exercise reduced IL-1 $\beta$ and also the NLRP3 hippocampal levels in HFD-induced obese rats, effect that was associated with increased expression of BDNF [35].

Even though data is scarce regarding the inhibitory effect of physical exercise on the activation of the inflammasome, the emerging information is promising for the use of physical exercise as a nonpharmacological treatment or a co-adjuvant therapy in depressive disorders. Additionally, there is a great body of literature about indirect examples of inhibition of inflammasome by physical exercise. For example, Kang and colleagues (2016) and Chirico and colleagues (2016) demonstrated a significant reduction of IL-1 $\beta$ (cytokine processed by the inflammasome) in the brain of HDF-treated rodents after submitting the animals to an endurance training $[79,80]$. As mentioned above, physical exercise-reduced hippocampal IL-1 $\beta$ levels have been extensively described in different physical activity protocols and in different rodent strains $[26,64,78-81,84]$.

\section{Increasing neopterin with physical exercise to prevent and treat depression}

Neopterin is a byproduct of the de novo synthesis pathway of tetrahydrobiopterin (BH4). Increased levels are produced under conditions of cellular stress induced by inflammatory stimuli, including IFN- $\gamma$, LPS (bacterial lipopolysaccharide), hydrogen peroxide $\left(\mathrm{H}_{2} \mathrm{O}_{2}\right)$, among others [85-87]. The literature suggests that in humans, macrophages and monocytes would be the main peripheral producers of neopterin [88]. In this way, an increase in neopterin levels in biological fluids has been considered a sensitive marker of immune system activation. Elevated neopterin levels have been described in diseases with an inflammatory component and also in high-intensity physical exercise [89-93].

The central production of neopterin was not considered till 2013 when Kuehne et al., (2013) [94] suggested that neopterin would be produced in the CNS based on i) an estimated low quotient (1/40) for neopterin to cross the blood-brain barrier (BBB) [95] and ii) the neopterin levels found in CSF being higher than the plasma or serum, for example, in patients with neurological diseases with intact BBB [94]. In agreement with this proposal of a central origin for neopterin, 
our group demonstrated that the pteridine is produced and secreted from hippocampal slices and striatal astrocytes in conditions of mitochondrial toxicity $[96,97]$.

The number of investigations regarding increased plasma and urinary neopterin concentrations in athletes and animals after highthroughput exercise have been increasing since 1992 [91-93,98101]. Peripheral neopterin levels have been correlated with immune system activation and oxidative stress. Elevated neopterin levels have been described in the urine of rugby players shortly after playing and correlated with increased oxidative stress and inflammatory status, contributing to muscle damage [92]. De Lucas et al. (2013) [99] studied neopterin concentration in an ultra-endurance MultiSport Brazil competition (alternating off-road running, mountain biking and kayaking; 90km) and found that several markers of muscle damage, oxidative metabolism, and immune system activation were increased in serum samples from these athletes. The authors postulated that the increased neopterin concentration indicating the activation of the immune system could still serve as a marker of extreme physical activity or overtraining [99]. A significant increase in the urinary neopterin concentration was also demonstrated in ultra-marathon runners which was associated with increased oxidative stress, inflammatory response, temporary impairment of renal function, fatigue and reduced physical performance [100].

Although there are more thousands of publications in the literature describing increased plasma/serum neopterin in different human conditions, including physical exercise, little is known about the pteridine functions in the body. Some authors have reported neopterin as an exclusive excretion product, while others have associated high concentrations of neopterin (higher than those encountered in pathological conditions) with oxidative stress, inflammation, and apoptosis [102-105], as observed during high-intensity physical exercise when the immune system is activated. However, our group has recently demonstrated that neopterin has antioxidant and antiinflammatory properties $[97,106]$. The intracerebroventricular (i.c.v.) administration of neopterin improves the resistance to oxidative stress in healthy adult Swiss mice cerebral cortex by increasing the content of glutathione and the activity of the glutathione-metabolizing antioxidant enzymes, glutathione peroxidase and glutathione reductase

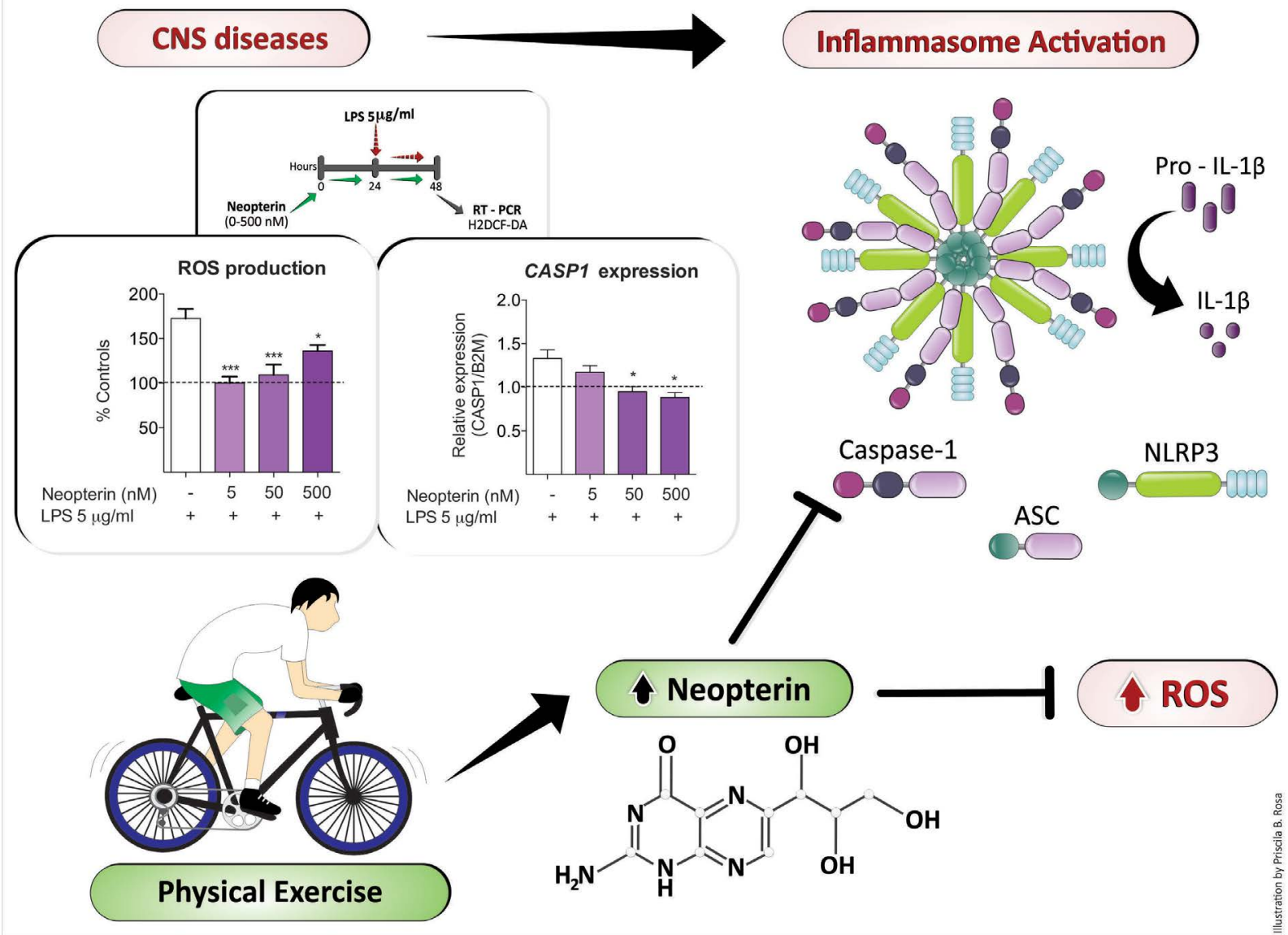

Figure 1. Hypothesis based on evidence: Moderate intensity physical exercise would increase neopterin concentrations in brain cells, preventing oxidative stress induction and inflammasome activation, and inducing, therefore, anti-depressant effects. Neopterin prevents oxidative stress and inflammasome assembly in human neurons. Cultured primary neurons were obtained from 16-19 week old fetuses collected following therapeutic termination with informed consent. All experiments followed the ethical standards in accordance with the Australian National Statement on Ethical Conduct in Human Research (2007) (HREC Application REF 5201300330). Primary neuronal culture was prepared from the mixed brain cell cultures, and maintained using a protocol adapted from previously described by Guillemin et al. 2003 [114]. Cells were treated according to the scheme: cells were pre-conditioned with neopterin $(5-500 \mathrm{nM})$ for 24 hours. After that, LPS was added to the medium without removing neopterin. After 24 hours of co-exposure, the effects were evaluated by measuring the oxidation of dichlorodihydrofluorescein diacetate (H2DCF-DA) (A) and the gene expression of caspase-1 (B). For H2DCF-DA oxidation, cells were incubated with the probe (10 $\mathrm{mM}$ ) for $30 \mathrm{~min}$. H2DCF-DA oxidation was indicated as percentage of fluorescence intensity compared to the controls [115]. Caspase-1 gene expression was determined by quantitative qRT-PCR. The sequence primers used for CASP1 mRNA detection were CTCAGGCTCAGAAGGGAATG (forward) and CGCTGTACCCCAGATTTTGT (reverse); and for B2M were AGGCTATCCAGCGTACTCCA (forward) and CGGCAGGCATACTCATCTTT (reverse). Gene expression is shown as the ratio of the studied transcripts relative to B2M measured in triplicate. Values are presented as mean \pm SEM of three independent experiments. ${ }^{*} P<0.05,{ }^{* * *} P<0.001$ vs. LPS (One-Way ANOVA followed by the Dunnett's post- hoc test). 
[97]. In addition, neopterin i.c.v. injection decreased IL-6 levels in the brain of LPS-treated IL-10 knockout aged mice [96]. Furthermore, our group has also demonstrated that neopterin is an endogenous cognitive enhancer by facilitating aversive memory acquisition and by reducing the threshold to generate the hippocampal long-term potentiation [96], an essential mechanism for memory formation [107]. Cognition and learning are two processes known to be compromised in individuals affected by depressive conditions, pointing out that facilitating increasing concentrations of neopterin in the brain; i.e. induced by aerobic and moderate physical exercise, would inhibit inflammation and ameliorate brain cognitive function among others. In this scenario, we have observed that human neurons pre-exposed to neopterin are more resistant to oxidative stress and to inflammasome activation under an inflammatory stimulus (Figure 1). To our knowledge, this is the first report of inflammasome assembly inhibition in human neurons by an endogenous compound. Figure $1 \mathrm{~A}$ shows that human primary neurons pre-incubated $24 \mathrm{~h}$ with neopterin $(5-500 \mathrm{nM})$ reduced the oxidation of dichlorodihydrofluorescein diacetate (H2DCF-DA) when stimulated with LPS $(5 \mu \mathrm{g} / \mathrm{mL} ; 24 \mathrm{~h})$. LPS increased reactive oxygen species (ROS) production up to $60 \%$, while all tested neopterin concentrations prevented this effect $\left[F_{(3,16)}=12.33 ; P<0.001\right]$. ROS production has been extensively studied as an activator of inflammasome assembly [108110]. Due to the antioxidant properties of neopterin, increased levels of the molecule become a strong candidate for inflammasome inhibition. In addition, Figure $1 \mathrm{~B}$ shows that neopterin pre-conditioning (50 and $500 \mathrm{nM}$ ) also prevented the LPS-induced caspase-1 gene expression $\left[F_{(3,5)}=7.90 ; P<0.05\right]$, a protein essential for the inflammasome assembly.

The inhibition of the inflammasome activation by neopterin may be one of the mechanisms by which the pteridine exerts its cognitive enhancer effects, since NLRP3 and NLRP1 inflammasomes activation seems to play a role in the cognitive impairment observed in experimental models characterized by neuroinflammation $[30,31,111]$. "In addition, previous studies have revealed that both caspase- 1 and ASC are involved in cognitive impairments induced, respectively, by Escherichia coli neonatal infection followed by LPS exposure in adulthood, and by mutations in $\beta$-amyloid precursor protein and presenilin-1, mimicking Alzheimer's disease in mice [112,113].”

\section{Future directions}

As pointed above, there is no data in the current literature about the regulation of neopterin production by nerve cells, or about the modulatory effect of the pteridine on the inflammasome assembly by physical exercise. However, some new details about the antioxidant and anti-inflammatory properties of this endogenous compound in the CNS, and its capacity to positively enhance cognition have been recently revealed by our group. It should be here remarked, that all these three systems that can be experimentally enhanced by neopterin, have been demonstrated to be compromised in depressive individuals.

Up-to-date neopterin levels have been investigated peripherally (urine or serum/plasma) in humans or animal studies under different high intensity physical activity protocols. High-intensity physical activity protocols are known to compromise memory and to induce oxidative stress and inflammation [60]. Therefore, we hypothesize that neopterin brain production could be modulated under different aerobic moderate intensity or endurance exercise protocols, preventing oxidative stress induction, inflammasome activation, enhancing cognition, and, therefore, inducing anti-depressant effects.

\section{Acknowledgments}

The authors are grateful to Ted Griswold for language editing.
This work was supported by grants from CNPq (Conselho Nacional de Desenvolvimento Científico e Tecnológico, Brazil), CAPES (Coordenação de Aperfeiçoamento de Pessoal de Nível Superior, Brazil), FAPESC/CNPq (Programa de Apoio a Núcleos de Excelência PRONEX; NENASC Project). Guillemin G is funded by the Australian Research Council (Future Fellowship) at the Macquarie University. Latini A is a CNPq fellow.

\section{References}

1. Berton O, Nestler EJ (2006) New approaches to antidepressant drug discovery: beyond monoamines. Nat Rev Neurosci 7: 137-151. [Crossref]

2. Kessler RC, Berglund P, Demler O, Jin R, Koretz D, et al. (2003) The Epidemiology of Major Depressive Disorder: Results from the National Comorbidity Survey Replication (NCS-R). JAMA 289: 3095-3105. [Crossref]

3. Greden JF (2001) The burden of disease for treatment-resistant depression. J Clin Psychiatry 62 Suppl 16: 26-31. [Crossref]

4. Papakostas G, Ionescu D (2015) Towards New Mechanisms: An Update on Therapeutics for Treatment-Resistant Major Depressive Disorder. Molecular Psychiatry 20: 1142 1150 .

5. Kokacya MH, Bahceci B, Bahceci I, Dilek AR, Dokuyucu R (2014) Prolidase Activity and Oxidative Stress in Patients with Major Depressive Disorder. Psychiatria Danubina 26: 314-318.

6. Tobe EH (2013) Mitochondrial Dysfunction, Oxidative Stress, and Major Depressive Disorder. Neuropsychiatric Disease and Treatment 9: 567-573. [Crossref]

7. Wang H, Warner-Schmidt J, Varela S, Enikolopov G, Greengard P, et al. (2015) Norbin Ablation Results in Defective Adult Hippocampal Neurogenesis and Depressive-like Behavior in Mice. Proceedings of the National Academy of Sciences of the United States of America 112: 9745-9750. [Crossref]

8. Slavich GM, Irwin MR (2014) From stress to inflammation and major depressive disorder: a social signal transduction theory of depression. Psychol Bull 140: 774-815. [Crossref]

9. Svensson M, Lexell J, Deierborg T (2015) Effects of Physical Exercise on Neuroinflammation, Neuroplasticity, Neurodegeneration, and Behavior: What We Can Learn From Animal Models in Clinical Settings. Neurorehabilitation and Neural Repair 29: 577-589. [Crossref]

10. Stinchcombe JC, Griffiths GM (2007) Secretory mechanisms in cell-mediated cytotoxicity. Annu Rev Cell Dev Biol 23: 495-517. [Crossref]

11. Moqbel R, Coughlin JJ (2006) Differential Secretion of Cytokines. Science's STKE?: Signal Transduction Knowledge Environment pe26.

12. Jolly C, Sattentau QJ (2007) Regulated secretion from CD4+ T cells. Trends Immunol 28: 474-481. [Crossref]

13. Stow JL1, Low PC, Offenhäuser C, Sangermani D (2009) Cytokine secretion in macrophages and other cells: pathways and mediators. Immunobiology 214: 601-612. [Crossref]

14. Stow JL, Manderson AP, Murray RZ (2006) SNAREing immunity: the role of SNAREs in the immune system. Nat Rev Immunol 6: 919-929. [Crossref]

15. Nickel W (2003) The mystery of nonclassical protein secretion. A current view on cargo proteins and potential export routes. Eur J Biochem 270: 2109-2119. [Crossref]

16. Eder C (2009) Mechanisms of interleukin-1beta release. Immunobiology 214: 543-553. [Crossref]

17. Thornberry NA, Bull HG, Calaycay JR, Chapman KT, Howard AD, et al. (1992) A Novel Heterodimeric Cysteine Protease Is Required for Interleukin-1 Beta Processing in Monocytes. Journal Article Nature 356: 768-774. [Crossref]

18. Coeshott C, Ohnemus C, Pilyavskaya A, Ross S, Wieczorek M, et al. (1999) Converting Enzyme-Independent Release of Tumor Necrosis Factor $\alpha$ and IL- $1 \alpha$ from a Stimulated Human Monocytic Cell Line in the Presence of Activated Neutrophils or Purified Proteinase 3. Proceedings of the National Academy of Sciences of the United States of America 96: 6261-6266.

19. Dinarello CA (1996) Biologic basis for interleukin-1 in disease. Blood 87: 2095-2147. [Crossref]

20. Martinon F, Burns K, Tschopp J (2002) The Inflammasome: A Molecular Platform Triggering Activation of Inflammatory Caspases and Processing of proIL-Beta. Journal Article Mol Cell 10: 417-426. 
21. Boatright KM, Renatus M, Scott FL, Sperandio S, Shin H, et al. (2003) A Unified Model for Apical Caspase Activation. Molecular Cell 11: 529-541. [Crossref]

22. Broz P, Newton K, Lamkanfi M, Mariathasan S, Dixit VM, et al. (2010) Redundant Roles for Inflammasome Receptors NLRP3 and NLRC4 in Host Defense against Salmonella. The Journal of Experimental Medicine 207: 1745-1755.

23. Liu Z, Zaki MH, Vogel P, Gurung P, Finlay BB, et al. (2012) Role of Inflammasomes in Host Defense against Citrobacter Rodentium Infection. Journal of Biological Chemistry 287: 16955-16964.

24. Liu W, Sheng H, Xu Y, Liu Y, Lu J, et al. (2013a) Swimming Exercise Ameliorates Depression-like Behavior in Chronically Stressed Rats: Relevant to Proinflammatory Cytokines and IDO Activation. Behavioural Brain Research 242: 110-116. [Crossref]

25. Thakkar R, Wang R, Sareddy G, Wang J, Thiruvaiyaru D, et al. (2016) NLRP3 Inflammasome Activation in the Brain after Global Cerebral Ischemia and Regulation by 17ß-Estradiol. Oxid Med Cell Longev 2016: 8309031.

26. Liu HD, Li W, Chen ZR, Hu YC, Zhang DD, et al. (2013b) Expression of the NLRP3 Inflammasome in Cerebral Cortex after Traumatic Brain Injury in a Rat Model. Neurochem Res 38: 2072-2083. [Crossref]

27. Ma J, Xiao W, Wang J, Wu J, Ren J, et al. (2016) Propofol Inhibits NLRP3 Inflammasome and Attenuates Blast-Induced Traumatic Brain Injury in Rats. Inflammation 39: 2094 2103. [Crossref]

28. Feng L, Chen Y, Ding R, Fu Z, Yang S, et al. (2015) P2X7R Blockade Prevents NLRP3 Inflammasome Activation and Brain Injury in a Rat Model of Intracerebral Hemorrhage: Involvement of Peroxynitrite. J Neuroinflammation 12: 190. [Crossref]

29. Kim KH, Andreazza AC, Elmi N, Chen W, Young LT (2016) Nod-like Receptor Pyrin Containing 3 (NLRP3) in the Post-Mortem Frontal Cortex from Patients with Bipolar Disorder: A Potential Mediator between Mitochondria and Immune-Activation. Journal of Psychiatric Research 72: 43-50. [Crossref]

30. Tan C, Zhang J, Tan M, Chen H, Meng D, et al. (2015) NLRP1 Inflammasome Is Activated in Patients with Medial Temporal Lobe Epilepsy and Contributes to Neuronal Pyroptosis in Amygdala Kindling-Induced Rat Model. Journal of Neuroinflammation 12: $1-12$.

31. Heneka MT, Kummer MP, Stutz A, Delekate A, Schwartz S, et al. (2013) NLRP3 Is Activated in Alzheimer's Disease and Contributes to Pathology in APP/PS1 Mice. Journal Article Nature 493: 674-678. [Crossref]

32. Codolo G, Plotegher N, Pozzobon T, Brucale M, Tessari I, et al. (2013) Triggering of Inflammasome by Aggregated Alpha-Synuclein, an Inflammatory Response in Synucleinopathies. Journal Article PLoS One 8: e55375.

33. Halle A, Hornung V, Petzold GC, Stewart CR, Monks BG, et al. (2008) The NALP3 Inflammasome Is Involved in the Innate Immune Response to Amyloid-Beta. Journal Article Nat Immunol 9: 857-865.

34. Alcocer-Gómez E, Miguel M, Casas-Barquero N, Núñez-Vasco J, Sánchez-Alcazar JA, et al. (2014) NLRP3 Inflammasome Is Activated in Mononuclear Blood Cells from Patients with Major Depressive Disorder. Brain, Behavior, and Immunity 36: 111-17. [Crossref]

35. Cai M, Wang H, Li J, Zhang Y, Xin L, et al. (2016) The Signaling Mechanisms of Hippocampal Endoplasmic Reticulum Stress Affecting Neuronal Plasticity-Related Protein Levels in High Fat Diet-Induced Obese Rats and the Regulation of Aerobic Exercise. Brain, Behavior, and Immunity 57: 347-359.

36. Pan Y, Chen XY, Zhang QY, Kong LD (2014) Microglial NLRP3 Inflammasome Activation Mediates IL-1 $\beta$-Related Inflammation in Prefrontal Cortex of Depressive Rats. Brain, Behavior, and Immunity 41: 90-100. [Crossref]

37. Wong M-L, Inserra A, Lewis MD, Mastronardi CA, Leong L, et al. (2016) Inflammasome Signaling Affects Anxiety- and Depressive-like Behavior and Gut Microbiome Composition. Molecular Psychiatry 21: 1-9.

38. Xu Y, Sheng H, Bao Q, Wang Y, Lu J, et al. (2016) NLRP3 Inflammasome Activation Mediates Estrogen Deficiency-Induced Depression- and Anxiety-like Behavior and Hippocampal Inflammation in Mice. Brain, Behavior, and Immunity 56: 175-186.

39. González-Gross M, Meléndez A (2013) Sedentarism, Active Lifestyle and Sport: Impact on Health and Obesity Prevention. Nutrición Hospitalaria 28 Suppl 5: 89-98. [Crossref]

40. Babyak M, Blumenthal JA, Herman S, Khatri P, Doraiswamy M, et al. (2000) Exercise Treatment for Major Depression: Maintenance of Therapeutic Benefit at 10 Months. Psychosomatic Medicine 62: 633-638. [Crossref]

41. Warburton DER, Nicol CW, Bredin SSD (2006) Health Benefits of Physical Activity:
The Evidence. Canadian Medical Association Journal 174: 801-809. [Crossref]

42. WCRF World Cancer Research Fund/American Institute for Cancer Research (2007) Food, Nutrition, Physical Activity, and the Prevention of Cancer: A Global Perspective. Washington, DC: American Institute for Cancer Research.

43. Ades PA (2015) A Lifestyle Program of Exercise and Weight Loss Is Effective in Preventing and Treating Type 2 Diabetes Mellitus: Why Are Programs Not More Available? Preventive Medicine 80: 50-52. [Crossref]

44. Tonoli C, Heyman E, Roelands B, Buyse L, Cheung SS, et al. (2012) Effects of Different Types of Acute and Chronic (Training) Exercise on Glycaemic Control in Type 1 Diabetes Mellitus: A Meta-Analysis. Sports Medicine 42: 1059-1080. [Crossref]

45. Hayes SC, Rye S, Disipio T, Yates P, Bashford J, et al. (2013) Exercise for Health A Randomized, Controlled Trial Evaluating the Impact of a Pragmatic, Translational Exercise Intervention on the Quality of Life, Function and Treatment-Related Side Effects Following Breast Cancer. Breast Cancer Res Treat 137: 175-186. [Crossref]

46. O'Gorman DJ, Karlsson HKR, McQuaid S, Yousif O, Rahman Y, et al. (2006) Exercise Training Increases Insulin-Stimulated Glucose Disposal and GLUT4 (SLC2A4) Protein Content in Patients with Type 2 Diabetes. Diabetologia 49: 2983-2992. [Crossref]

47. Camacho TC, Roberts RE, Lazarus NB, Kaplan GA, Cohen RD (1991) Physical activity and depression: evidence from the Alameda County Study. Am J Epidemiol 134: 220231. [Crossref]

48. Hamer M, Molloy GJ, de Oliveira C, Demakakos P (2009) Persistent Depressive Symptomatology and Inflammation: To What Extent Do Health Behaviours and Weigh Control Mediate This Relationship? Brain, Behavior, and Immunity 23: 413-418.

49. Greenwood BN, Strong PV, Dorey A, Fleshner M (2007) Therapeutic Effects of Exercise: Wheel Running Reverses Stress-Induced Interference with Shuttle Box Escape. Behavioral Neuroscience 121: 992-1000. [Crossref]

50. Helgadóttir B, Hallgren M, Ekblom Ö, Forsell Y (2016) Training fast or slow? Exercise for depression: A randomized controlled trial. Prev Med 91: 123-131. [Crossref]

51. Hallgren M, Helgadóttir B, Herring MP, Zeebari Z, Lindefors N, et al. (2016) FollowUp, Exercise and Internet-Based Cognitive-behavioural Therapy for Depression: Multicentre Randomised Controlled Trial with 12-Month. The British Journal of Psychiatry 209: 414-420.

52. Carneiro LSF, Fonseca AM, Vieira-Coelho MA, Mota MP, Vasconcelos-Raposo J (2015) Effects of Structured Exercise and Pharmacotherapy vs. Pharmacotherapy for Adults with Depressive Symptoms: A Randomized Clinical Trial. Journal of Psychiatric Research 71: 48-55. [Crossref]

53. Schuch FB, Vasconcelos-Moreno MP, Borowsky C, Zimmermann AB, Rocha NS, et al. (2015) Exercise and Severe Major Depression: Effect on Symptom Severity and Quality of Life at Discharge in an Inpatient Cohort Journal of Psychiatric Research 61: 25-32. [Crossref]

54. Dimeo F, Bauer M, Varahram I, Proest G, Halter U (2001) Benefits from Aerobic Exercise in Patients with Major Depression: A Pilot Study. British Journal of Sports Medicine 35: 114-117. [Crossref]

55. Nabkasorn C, Miyai N, Sootmongkol A, Junprasert S, Yamamoto H, et al. (2006) Effects of Physical Exercise on Depression, Neuroendocrine Stress Hormones and Physiological Fitness in Adolescent Females with Depressive Symptoms. European Journal of Public Health 16: 179-184.

56. Jelalian E, Jandasek B, Wolff JC, Seaboyer LM, Jones RN, et al. (2016) CognitiveBehavioral Therapy Plus Healthy Lifestyle Enhancement for Depressed, Overweight/ Obese Adolescents: Results of a Pilot Trial. J Clin Child Adolesc Psychol 16: 1-10. [Crossref]

57. Blumenthal JA, Babyak MA, Moore KA, Craighead WE, Herman S, et al. (1999) Effects of Exercise Training on Older Patients with Major Depression. Archives of Internal Medicine 159: 2349-2356. [Crossref]

58. Makizako H, Tsutsumimoto K, Doi T, Hotta R, Nakakubo S, et al. (2015) Effects of exercise and horticultural intervention on the brain and mental health in older adults with depressive symptoms and memory problems: study protocol for a randomized controlled trial [UMIN000018547]. Trials 16: 499. [Crossref]

59. Meyer JD, Koltyn KF, Stegner AJ, Kim JS, Cook DB3 (2016) Relationships between serum BDNF and the antidepressant effect of acute exercise in depressed women. Psychoneuroendocrinology 74: 286-294. [Crossref]

60. Cunha MP, Oliveira Á, Pazini FL, Machado DG, Bettio LE, et al. (2013) The antidepressant-like effect of physical activity on a voluntary running wheel. Med Sci Sports Exerc 45: 851-859. [Crossref] 
61. Aguiar AS, Stragier E, Scheffer DL, Remor AP, Oliveira PA, et al. (2014) Effects of Exercise on Mitochondrial Function, Neuroplasticity and Anxio-Depressive Behavior of Mice. Neuroscience 271: 56-63. [Crossref]

62. Eyre H, Baune BT (2012) Neuroimmunological effects of physical exercise in depression. Brain Behav Immun 26: 251-266. [Crossref]

63. Aguiar AS, Speck AE, Prediger RDS, Kapczinski F, Pinho RA (2008) Downhill Training Upregulates Mice Hippocampal and Striatal Brain-Derived Neurotrophic Factor Levels. Journal of Neural Transmission 115: 1251-1255.

64. Sigwalt AR, Budde H, Helmich I, Glaser V, Ghisoni K, et al. (2011) Molecular Aspects Involved in Swimming Exercise Training Reducing Anhedonia in a Rat Model of Depression. Neuroscience 192: 661-674. [Crossref]

65. Figueiredo CP, Pamplona FA, Mazzuco TL, Aguiar AS, Walz R, et al. (2010) Role of the Glucose-Dependent Insulinotropic Polypeptide and Its Receptor in the Central Nervous System: Therapeutic Potential in Neurological Diseases. Behavioural Pharmacology 21: 394-408.

66. Kiuchi T, Lee H, Mikami T (2012) Regular exercise cures depression-like behavior via VEGF-Flk-1 signaling in chronically stressed mice. Neuroscience 207: 208-217. [Crossref]

67. Gioscia-Ryan RA, Battson ML, Cuevas LM, Zigler MC, Sindler AL, et al. (2016) Voluntary Aerobic Exercise Increases Arterial Resilience and Mitochondrial Health with Aging in Mice. Aging 8: 11. [Crossref]

68. Jiang P, Dang RL, Li HD, Zhang LH, Zhu WY, et al. (2014) The Impacts of Swimming Exercise on Hippocampal Expression of Neurotrophic Factors in Rats Exposed to Chronic Unpredictable Mild Stress. Evidence-Based Complementary and Alternative Medicine 2014: 729827.

69. Bullitt E (1990) Expression of c-fos-like protein as a marker for neuronal activity following noxious stimulation in the rat. J Comp Neurol 296: 517-530. [Crossref]

70. Otsuka T, Nishii A, Amemiya S, Kubota N, Nishijima T, et al. (2016) Effects of Acute Treadmill Running at Different Intensities on Activities of Serotonin and CorticotropinReleasing Factor Neurons, and Anxiety- and Depressive-like Behaviors in Rats. Behavioural Brain Research 298: 44-51. [Crossref]

71. Van Praag H, Christie BR, Sejnowski TJ, Gage FH (1999) Running enhances neurogenesis, learning, and long-term potentiation in mice. Proc Natl Acad Sci U S A 96: 13427-13431. [Crossref]

72. Thundyil J, Pavlovski D, Sobey CG, Arumugam TV (2012) Adiponectin receptor signalling in the brain. Br J Pharmacol 165: 313-327. [Crossref]

73. Leo R, Di Lorenzo G, Tesauro M, Cola C, Fortuna E, et al. (2006) Decreased plasma adiponectin concentration in major depression. Neurosciences Letters 407: 211-213.

74. Narita K, Murata T, Takahashi T, Kosaka H, Omata N, et al. (2006) Plasma levels of adiponectin and tumor necrosis factor-alpha in patients with remitted major depression receiving long-term maintenance antidepressant therapy. Progress in NeuroPsychopharmacology \& Biological Psychiatry 30: 1159-1162.

75. Parachikova A, Nichol KE, Cotman CW (2008) Short-term exercise in aged Tg2576 mice alters neuroinflammation and improves cognition. Neurobiol Dis 30: 121-129. [Crossref]

76. Martin SA, Pence BD, Greene RM, Johnson SJ, Dantzer R, et al. (2013) Effects of voluntary wheel running on LPS-induced sickness behavior in aged mice. Brain Behav Immun 29: 113-123. [Crossref]

77. Hare BD, Beierle JA, Toufexis DJ, Hammack SE, Falls WA (2014) Exercise-Associated Changes in the Corticosterone Response to Acute Restraint Stress: Evidence for Increased Adrenal Sensitivity and Reduced Corticosterone Response Duration. Neuropsychopharmacology 39: 1262-1269. [Crossref]

78. Nichol KE, Poon WW, Parachikova AI, Cribbs DH, Glabe CG, et al. (2008) Exercise Alters the Immune Profile in Tg2576 Alzheimer Mice toward a Response Coincident with Improved Cognitive Performance and Decreased Amyloid. Journal of Neuroinflammation 5: 13 .

79. Chirico E, Di Cataldo V, Chauveau F, Geloën A, Patsouris D, et al. (2016) MRI biomarkers of exercise-induced improvement of oxidative stress and inflammation in the brain of old high fat fed ApoE -/-mice. J Physiol 594: 6969-6985.

80. Kang EB, Koo JH, Jang YC, Yang CH, Lee Y, et al. (2016) Neuroprotective Effects of Endurance Exercise Against High-Fat Diet-Induced Hippocampal Neuroinflammation. J Neuroendocrinol 28. [Crossref]

81. Tang MM, Lin WJ, Pan YQ, Guan XT, Li YC (2016) Hippocampal Neurogenesis Dysfunction Linked to Depressive-like Behaviors in a Neuroinflammation Induced
Model of Depression. Physiology and Behavior 161: 166-173.

82. Mardare C, Krüger K, Liebisch G, Seimetz M, Couturier A, et al. (2016) Endurance and Resistance Training Affect High Fat Diet-Induced Increase of Ceramides, Inflammasome Expression, and Systemic Inflammation in Mice. Journal of Diabetes Research: 4536470.

83. Wang Y, Xu Y, Sheng H, Ni X, Lu J (2016) Exercise Amelioration of Depressionlike Behavior in OVX Mice Is Associated with Suppression of NLRP3 Inflammasome Activation in Hippocampus. Behavioural Brain Research 307: 18-24.

84. Gomes da Silva S, Simões PS, Mortara RA, Scorza FA, Cavalheiro EA, et al. (2013) Exercise-induced hippocampal anti-inflammatory response in aged rats. Journal of Neuroinflammation 10: 61-66.

85. Troppmair J, Nachbaur K, Herold M, Aulitzky W, Tilg H, et al. (1988) In-vitro and invivo studies on the induction of neopterin biosynthesis by cytokines, alloantigens and lipopolysaccharide (LPS). Clin Exp Immunol 74: 392-397. [Crossref]

86. Franscini N, Blau N, Walter RB, Schaffner A, Schoedon G (2003) Critical Role of Interleukin-1beta for Transcriptional Regulation of Endothelial 6-Pyruvoyltetrahydropterin Synthase. Arterioscler Thromb Vasc Biol 23: e50-3. [Crossref]

87. Ishii M, Shimizu S, Wajima T, Hagiwara T, Negoro T, et al. (2005) Reduction of GTP Cyclohydrolase I Feedback Regulating Protein Expression by Hydrogen Peroxide in Vascular Endothelial Cells. Journal of Pharmacological Sciences J Pharmacol Sci 97: 299-302.

88. Werner ER, Werner-Felmayer G, Fuchs D, Hausen A, Reibnegger G, et al. (1990) Tetrahydrobiopterin Biosynthetic Activities in Human Macrophages, Fibroblasts, THP-1, and T 24 Cells: GTP-Cyclohydrolase I Is Stimulated by Interferon-gamma, and 6-Pyruvoyl Tetrahydropterin Synthase and Sepiapterin Reductase Are Constitutively Present. Journal of Biological Chemistry 265: 3189-3192.

89. Chittiprol S, Venkatasubramanian G, Neelakantachar N, Babu SV, Reddy NA, et al (2010) Oxidative Stress and Neopterin Abnormalities in Schizophrenia: A Longitudinal Study. Journal of Psychiatric Research 44: 310-313. [Crossref]

90. Hagberg L, Cinque P, Gisslen M, Brew BJ, Spudich S, et al. (2010) Cerebrospinal Fluid Neopterin: An Informative Biomarker of Central Nervous System Immune Activation in HIV-1 Infection. AIDS Research and Therapy 7: 15.

91. Lindsay A, Draper N, Lewis J, Gieseg SP, et al. (2015) Positional demands of professional rugby. Eur J Sport Sci 15: 480-487. [Crossref]

92. Lindsay A, Healy J, Mills W, Lewis J, Gill N, et al. (2016) Impact-Induced Muscle Damage and Urinary Pterins in Professional Rugby: 7,8-Dihydroneopterin Oxidation by Myoglobin. Scandinavian Journal of Medicine and Science in Sports 26: 329-337.

93. Lindsay A, Janmale T, Draper N, Gieseg SP (2014) Measurement of Changes in Urinary Neopterin and Total Neopterin in Body Builders Using SCX HPLC. Pteridines 25: 53-63.

94. Kuehne LK, Reiber H, Bechter K, Hagberg L, Fuchs D (2013) Cerebrospinal Fluid Neopterin Is Brain-Derived and Not Associated with Blood-CSF Barrier Dysfunction in Non-Inflammatory Affective and Schizophrenic Spectrum Disorders. Journal of Psychiatric Research 47: 1417-1422. [Crossref]

95. Hagberg L, Dotevall L, Norkrans G, Larsson M, Wachter H, et al. (1993) Cerebrospinal Fluid Neopterin Concentrations in Central Nervous System Infection. The Journal of Infectious Diseases 168: 1285-1288.

96. Ghisoni K, Aguiar AS Jr, de Oliveira PA, Matheus FC, Gabach L, et al. (2016) Neopterin acts as an endogenous cognitive enhancer. Brain Behav Immun 56: 156-164. [Crossref]

97. Ghisoni K, Latini A (2015) Is Brain-Derived and Not Associated with Blood-CSF Barrier Dysfunction in Non- Inflammatory Affective and Schizophrenic Spectrum Disorders. Journal of Psychiatric Research 63: 141-142.

98. Sprenger H, Jacobs C, Nain M, Gressner AM, Prinz H, et al. (1992) Enhanced Release of Cytokines, Interleukin-2 Receptors, and Neopterin after Long-Distance Running. Clin Immunol Immunopathol 63: 188-195. [Crossref]

99. De Lucas RD, Caputo F, de Souza KM, Sigwalt AR, Ghisoni K, et al. (2013) Increased Platelet Oxidative Metabolism, Blood Oxidative Stress and Neopterin Levels after Ultra-Endurance Exercise. Journal of Sports Sciences 0: 1-9. [Crossref]

100. Mrakic-Sposta S, Gussoni M, Moretti S, Pratali L, Giardini G, et al. (2015) Effects of Mountain Ultra-Marathon Running on ROS Production and Oxidative Damage by Micro-Invasive Analytic Techniques. PLoS ONE 10: e0141780.

101. Tilz GP, Domej W, Diez-Ruiz A, Weiss G, Brezinschek R, et al. (1993) Increased Immune Activation during and after Physical Eexercise. Immunobiology 188: 194 202. [Crossref] 
102. Weiss G, Fuchs D, Hausen A, Reibnegger G, Werner ER, et al. (1993) Neopterin Modulates Toxicity Mediated by Reactive Oxygen and Chloride Species. FEBS Letters 321: 89-92.

103. Hoffmann G, Schobersberger W, Frede S, Pelzer L, Fandrey J, et al. (1996) Neopterin Activates Transcription Factor Nuclear Factor-Kappa B in Vascular Smooth Muscle Cells. FEBS Lett 391: 181-184

104. Schobersberger W, Hoffmann G, Hobisch-Hagen P, Böck G, Völkl H, et al. (1996) Neopterin and 7,8-Dihydroneopterin Induce Apoptosis in the Rat Alveolar Epithelial Cell Line L2. FEBS Letters 397: 263-268.

105. Cirillo P, Pacileo M, Rosa S, Calabrò P, Gargiulo A, et al. (2006) Neopterin Induces pro-Atherothrombotic Phenotype in Human Coronary Endothelial Cells. Journal of Thrombosis and Haemostasis JTH 4: 2248-2255.

106. Ghisoni K, Martins RP, Barbeito L, Latini A (2015) Neopterin as a Potential Cytoprotective Brain Molecule. Journal of Psychiatric Research 71: 134-139.

107. Abraham WC, Logan B, Greenwood MJ, Dragunow M (2002) Induction and Experience-Dependent Consolidation of Stable Long-Term Potentiation Lasting Months in the Hippocampus." The Journal of Neuroscience 22: 9626-9634. [Crossref]

108. Zhou R, Yazdi AS, Menu P, Tschopp J (2011) A role for mitochondria in NLRP3 inflammasome activation. Nature 469: 221-225. [Crossref]

109. Nakahira K, Haspel JA, Rathinam VAK, Lee S, Dolinay T, et al. (2011) Autophagy Proteins Regulate Innate Immune Responses by Inhibiting the Release of
Mitochondrial DNA Mediated by the NALP3 Inflammasome. Nature Immunology 12: 222-230. [Crossref]

110. Alfonso-Loeches S, Ureña-Peralta JR, Morillo-Bargues MJ, La Cruz JO, Guerr C (2014) Role of Mitochondria ROS Generation in Ethanol-Induced NLRP3 Inflammasome Activation and Cell Death in Astroglial Cells. Frontiers in Cellular Neuroscience 8: 216. [Crossref]

111. Mawhinney LJ, de Vaccari Rivero J, Dale G, Keane RW, Bramlett HM (2011) Heightened Inflammasome Activation Is Linked to Age-Related Cognitive Impairment in Fischer 344 Rats. BMC Neuroscience 12: 123.

112. Bilbo SD, Biedenkapp JC, Der-Avakian A, Watkins LR, Rudy JW, et al. (2005) Neonatal Infection-Induced Memory Impairment after Lipopolysaccharide in Adulthood Is Prevented via Caspase-1 Inhibition. The Journal of Neuroscience 25: 8000-8009. [Crossref]

113. Couturier J, Stancu I, Schakman O, Pierrot N, Huaux F, et al. (2016) Activation of Phagocytic Activity in Astrocytes by Reduced Expression of the Inflammasome Component ASC and Its Implication in a Mouse Model of Alzheimer Disease. Journal of Neuroinflammation 13: 20.

114. Guillemin GJ, Croitoru-Lamoury J, Dormont D, Armati PJ, Brew BJ (2003) Quinolinic Acid Upregulates Chemokine Production and Chemokine Receptor Expression in Astrocytes. GLIA 41: 371-381.

115. De Almeida LMV, Piñeiro CC, Leite MC, Brolese G, Leal RB, et al. (2008) Protective Effects of Resveratrol on Hydrogen Peroxide Induced Toxicity in Primary Cortical Astrocyte Cultures. Neurochemical Research 33: 8-15.

Copyright: ( 2016 Martins RP. This is an open-access article distributed under the terms of the Creative Commons Attribution License, which permits unrestricted use, distribution, and reproduction in any medium, provided the original author and source are credited. 